\title{
Nitric oxide is not involved in Neisseria gonorrhoeae-induced cellular damage of human Fallopian tubes in vitro
}

\author{
KATHERINE P GARCÍA ${ }^{1}$, PAULINA S RUBILAR ${ }^{1}$, MACARENA F VARGAS ${ }^{1}$, HUGO \\ CÁRDENAS ${ }^{1,4}$, MIGUEL A RIOS ${ }^{1,4}$, PEDRO A ORIHUELA ${ }^{1,4}$, RENATO H VARGAS $^{2}$, \\ JUAN FUHRER ${ }^{2}$, JOHN E HECKELS ${ }^{3}$, MYRON CHRISTODOULIDES ${ }^{3}$ \\ and LUIS A VELÁSQUEZ ${ }^{1,4} *$
}

\author{
${ }^{1}$ Laboratorio de Inmunología de la Reproducción, Facultad de Química y Biología, Universidad de Santiago \\ de Chile, Santiago, Chile \\ ${ }^{2}$ Hospital San José, Santiago, Chile \\ ${ }^{3}$ Neisseria Research Group, Molecular Microbiology, Division of Infection, Inflammation and Repair, \\ University of Southampton Medical School, Southampton, England and \\ ${ }^{4}$ Centro para el Desarrollo de la Nanociencia y Nanotecnología (CEDENNA), Santiago, Chile.
}

\begin{abstract}
In the present study, we investigated whether cellular damage, as demonstrated by lactate dehydrogenase (LDH) release in the human fallopian tube (FT) infected by Neisseria gonorrhoeae (Ngo), correlated with high levels of nitric oxide synthase (NOS) mRNA and enzyme activity. Infection with Ngo induced a significant increase ( 35 -fold) in mRNA transcripts of the inducible isoform of NOS. Paradoxically, a reduction in NOS enzyme activity was observed in infected cultures, suggesting that gonococcal infection possibly influences translation of iNOS mRNA to the enzyme. In addition, treatment with the NOS inhibitor TRIM did not prevent gonococcal-induced cellular damage. In contrast, the addition of the inhibitor L-NAME induced a $40 \%$ reduction in $\mathrm{LDH}$ release, which correlated with a $\sim 50 \%$ reduction in gonococcal numbers. Moreover, treatment of normal FT explants with an exogenous NO donor, SNAP, did not induce significant cellular damage. Taken together, our data suggest that NO does not contribute to cellular damage during infection of the human FT with Neisseria gonorrhoeae.
\end{abstract}

Key terms: cellular damage, fallopian tubes, Neisseria gonorrhoeae, nitric oxide.

\section{INTRODUCTION}

Neisseria gonorrhoeae ( $\mathrm{Ngo}$ ) is the etiologic agent of gonorrhoeae and it infects primarily the mucosal epithelia of the male urethra and the lower female genital tract. In women, localized infection induces a mucopurulent cervicitis, which is frequently asymptomatic, but in approximately 10$25 \%$ of individuals [Cates et al., 1990; Grodstein and Rothman, 1994; Stacey et al., 1992], infection may ascend into the upper reproductive tract, including the fallopian tubes (FT). The host response to ascending infection can result in pelvic inflammatory disease (PID), which encompasses a range of inflammatory conditions including endometritis, peritonitis and FT salpingitis [Barrett and Taylor, 2005; Hoyme, 1990; McCormack, 1994]. Despite decades of public health initiatives and sexual health programs, gonococcal infection continues to be a problem worldwide and the chronic sequelae associated with PID, i.e. pelvic pain, FT damage, ectopic pregnancy and infertility are a considerable burden to the individual and to health services [Hoyme, 1990; McCormack, 1994]. 
Little is known at the cellular and molecular levels about the mechanisms involved in salpingitis that occur as a result of ascending gonococcal infection into the FT. The first reports that studied the pathogenesis of gonococcal-induced salpingitis used a culture model of ex vivo human FT organ explants [McGeeet al., 1976; Ward et al., 1974]. With this model, Ngo were shown to attach specifically to non-ciliated cells, a process mediated by the expression of pili and Opa protein adhesins [Gorby and Schaefer, 1992; McGeeet al., 1983]. However, Ngo infection induces damage to ciliated cells primarily, leading to a loss in ciliary activity and eventually to sloughing of cells from the epithelium [McGee et al., 1981; Stephens et al., 1987]. Cell death in the FT epithelium has been shown to correlate with the up-regulated production of tumour necrosis factor (TNF)$\alpha$ by the FT epithelium [McGee et al., 1992; McGee et al., 1996; Morales et al., 2006] and it is likely that gonococcal los lipooligosaccharides (LOS) and peptidoglycan fragments are key stimulators of this TNF- $\alpha$ release [Gregg et al., 1981; Melly et al., 1981; Melly et al., 1984]. In previous studies, we observed an apoptotic phenotype in cells of FT explant epithelium following $\mathrm{Ngo}$ infection and demonstrated that TNF- $\alpha$ mediated cell death by apoptosis in primary FT epithelial cells occurs in vitro [Morales et al., 2006]. Eventually, resolution of the inflammatory response and cell death involves a process of repair by infiltrating fibroblasts that leads to permanent scarring, eventual functional impairment of the tubes and irreversible infertility [Westrom and Wolnerhanssen, 1993].

It is clear that Ngo infection induces significant tissue damage in the FT, but the contribution of components of the inflammatory process other than TNF- $\alpha$ is not known. Previously, we identified the expression of multiple pro-inflammatory cytokines such as interleukin IL- $1 \alpha$, IL-1 $\beta$ and IL-6 in FT explants infected with Ngo [Maisey et al., 2003]. These cytokines and TNF- $\alpha$ are likely to play important roles in the innate defence of the FT, principally enhancing leukocytosis and oxidative respiratory burst responses [Dinarello, 2002] by means of production of reactive oxygen and nitrogen species such as nitric oxide (NO) [Busse and Mulsch, 1990; Kleinert et al., 2003; Thiemermann et al., 1993].

$\mathrm{NO}$ is a ubiquitous messenger molecule produced as a by-product of the cleavage of L-arginine to L-citrulline by the enzyme nitric oxide synthase (NOS) and to date four isoforms of NOS (neuronal (nNOS), inducible (iNOS), endothelial (eNOS) and mitochondrial (mNOS)) have been identified [Bruckdorfer, 2005]. In normal physiology, NO plays a critical role in the regulation of vascular tone and blood flow, neurotransmission, muscle relaxation, platelet reactivity and regulation of the immune system [Bruckdorfer, 2005]. In the FT, iNOS and eNOS are expressed and have been implicated in the regulation of embryo transport [Ekerhovd et al., 1999]. In addition, up-regulation of $\mathrm{NO}$ production has been detected in many inflammatory diseases induced by bacterial infection, including septicaemia, meningitis and peritonitis [Burgner et al., 1999; Kawakami et al., 2006; Klimenko, 2004; Plum et al., 1999], as well as being implicated in diabetes, migraine, cerebral ischemia, childhood brain tumours [Kao et al., 2003] and neurodegenerative disorders such as multiple sclerosis and Parkinson's disease [Hobbs et al., 1999]. There is also a considerable number of reports of bacteria such as Streptococcus pneumoniae, E. coli, Staphylococcus spp., Helicobacter pylori and Bordetella pertussis [Heiss et al., 1994] inducing in vitro NO production by various human epithelial [Goodrum and PoulsonDunlap, 2002; Kim et al., 2003; Witthoft et al., 1998] endothelial cells [Grimminger et al., 2007] and vascular smooth muscle cells [Busse and Mulsch, 1990], as well as neutrophils [Wheeler et al., 1997] and macrophages [Marriott et al., 2004; Smallwood et al., 2006].

It is likely that during salpingitis, upregulated expression of NOS could result in continuous production of high levels of NO with microbicidal activity. Conversely, the effects of NO might be manifest as host cell death and it has been reported for several cell lines that apoptotic cell death induced by LPS and the cytokines TNF- $\alpha$, IL-1 and 
IFN- $\alpha$ could be moderated through the use of NOS inhibitors [Blaise et al., 2005]. In the current paper, we investigated if the cellular damage that is observed in the fallopian tube infected by $\mathrm{Ngo}$ correlates with high levels of iNOS and eNOS mRNAs and increased activity of the enzyme. We also investigated whether NOS inhibitors had the potential to ameliorate this damage.

\section{MATERIALS AND METHODS}

\section{FT organ cultures}

FTs were obtained, after informed consent, from fertile donors undergoing hysterectomy for reasons unrelated to this study. The study protocols were approved by the Ethical and Scientific Review Committee of the Universidad de Santiago de Chile, in accordance with the Declaration of Helsinki. An exclusion criterion was the occurrence of sexually transmitted disease during the last year or a history of pelvic inflammatory disease. FT was processed immediately after removal, as described previously [Maisey, 2003]. Briefly, the muscle layer was dissected and discarded and the remaining mucosa was cut with a surgical blade into segments of 1 $\mathrm{cm}^{2}$ and placed in Dulbecco's modified Eagle's medium (DMEM; Hyclone, Utah, USA) in culture plates. Prior to infection, explants were maintained overnight at $37^{\circ} \mathrm{C}$ in an atmosphere of $5 \%(\mathrm{vol} / \mathrm{vol}) \mathrm{CO} 2$ in order to stabilize the tissue.

Bacterial strain, growth conditions and challenge of FT organ cultures

Ngo strain $\mathrm{P} 9$, variant $-17\left(\mathrm{Pil}^{+} \mathrm{Opab}^{+}\right)$has been described previously [Virji and Heckels, 1986] and was used for FT epithelial cell challenge experiments. Gonococci were grown routinely on GC agar, overnight at $37^{\circ} \mathrm{C}$ in $5 \%$ (vol/vol) $\mathrm{CO} 2$ and the strain phenotype was confirmed by examining the colony morphology with a stereomicroscope. Segments of FT originating from the same FT donor were infected intraluminally with
$100 \mu \mathrm{L}$ of different gonococcal doses $\left(3 \times 10^{5} \mathrm{cfu} / \mathrm{mL}, 3 \times 10^{6} \mathrm{cfu} / \mathrm{mL}\right.$ or $3 \times 10^{7}$ $\mathrm{cfu} / \mathrm{mL}$ ) for periods up to 24 hours. Control segments were treated with medium alone.

Measurement of cellular damage by lactate dehydrogenase activity assay

Measurement of lactate dehydrogenase $(\mathrm{LDH})$ activity was used to quantify cellular damage to FT organ cultures induced by infection with Ngo. The enzyme is released from cells with damaged membranes and was measured using the CytoTox 96® Non-Radio Cytotoxicity Assay (Promega, Madison, USA), according to the manufacturer's instructions. Briefly, $100 \mathrm{lL}$ of supernatant fluid were removed from duplicate infected and control explant cultures at 1, 3, 6, 12 and 24 hours and were transferred into 96 wells microtiter plates. LDH-assay reaction mixture $(50 \mathrm{lL})$ was added to each well, the plates incubated for $30 \mathrm{~min}$ at $37^{\circ} \mathrm{C}$ with $5 \%(\mathrm{vol} /$ vol) $\mathrm{CO} 2$ and the reaction stopped by the addition of stop solution (50 1L) to each well. Absorbance (A490nm) was read on an ELISA microplate reader (Biorad Model 550). As a positive control for maximum LDH release, FT explants were treated with Triton X-100. Cellular damage induced by gonococcal infection was expressed as a percentage relative to the damage induced by the detergent in control explants.

\section{Determination of iNOS and eNOS mRNA levels}

Total RNA was isolated by using TRIzol reagent (Invitogen, USA) and complementary (c)DNA synthesis was performed using oligo dT primers as described by Henriquez and colleagues [Henríquez et al., 2006]. Real Time PCR experiments were performed in a RotorGene 3000 instrument (Corbett Research, Australia) using the QUANTIMIX EASY SYG KIT (Biotools, Spain). The program to amplify peptidylprolyl isomerase A (PPIA) included $95^{\circ} \mathrm{C}$ for 2 minutes and 45 cycles of $95^{\circ} \mathrm{C}$ for 15 seconds; $60^{\circ} \mathrm{C}$ for 15 seconds; $72^{\circ} \mathrm{C}$ for 30 seconds and $83^{\circ} \mathrm{C}$ for 1 second by fluorescence acquisition. The 
program for iNOS and eNOS amplification included $95^{\circ} \mathrm{C}$ for 2 minutes and 45 cycles of $95^{\circ} \mathrm{C}$ for 20 seconds; $63^{\circ} \mathrm{C}$ for 20 seconds; $72^{\circ} \mathrm{C}$ for 30 seconds and $85^{\circ} \mathrm{C}$ for 1 second for fluorescence acquisition. The specificity of the amplified fragments was checked by using a melting curve analysis after the amplification program.

The primers sequences used to amplify the transcripts are detailed as follows: PPIA forward: GGGAAGTCCATCTACGGA PPIA reverse: ACATGCTTGCCATCCAAC eNOS forward: GACATTGAGAGCAAAG GGC eNOS reverse: CGGCTTGTCACCTC CTGG iNOS forward: GTGGTCCAACCT GCAGGTCT iNOS reverse: CATAGCGG ATGAGCTGAGCATT

The relative level of iNOS and eNOS mRNA were standardized against the levels of mRNA of the housekeeping gene PPIA in FT explants and expressed in arbitrary units (AU).

\section{Determination of nitric oxide synthase (NOS) activity}

The L- $\left[{ }^{3} \mathrm{H}\right]$ citrulline assay [Vasquez et al., 2004] was used to determine NOS activity from control uninfected and Ngo-infected FT explants after 12 hours. Briefly, FT explants $(n=5$ different donors $)$ were incubated for 60 minutes at $37^{\circ} \mathrm{C}$ in DMEM medium containing $100 \mu \mathrm{M}$ L-arginine and $4 \mu \mathrm{Ci} \mathrm{ml}{ }^{-1} \mathrm{~L}-\left[{ }^{3} \mathrm{H}\right]$ arginine. Supernatant fluids were then obtained from explants digested with $95 \%$ (vol/vol) formic acid and they were passed over Dowex-50W cation ion-exchange resin $(50 \mathrm{ml} \times 8-200 \mathrm{~mm}$ column) and the concentration of L$\left[{ }^{3} \mathrm{H}\right]$ citrulline was determined in the eluate with a liquid scintillation counter (LKB Wallac model 1217 RackB).

Treatment with nitric oxide (NO) donors and inhibitors

FT explants from the same individual were infected over time with 100 lL of Dulbecco's modified Eagle's medium

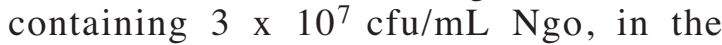
presence or absence of the NO inhibitors $\mathrm{N}(\mathrm{G})$-nitro-L-arginine methyl ester (LNAME, 500 1M; Sigma, St. Louis, USA) or 1-(2-trifluoromethylphenyl) imidazole (TRIM, 500 1M; Calbiochem). Uninfected explants were treated with the NO donor $\mathrm{S}$ Nitroso-N-penicillamine (SNAP, 100-1000 IM; Calbiochem). Uninfected explants, with and without NO inhibitors or donor were used as controls.

\section{Statistical analysis}

Data were expressed as mean and standard error and statistical analysis was performed using one way analysis of variance (ANOVA) or Wilcoxon Test. A MannWhitney test was used to analyze the data from Real Time PCR. Differences were considered statistically significant if the $P$ value was less than 0.05 .

\section{RESULTS}

Infection with Ngo induces dose-dependent cellular damage in FT organ explants

Over time, the cumulative levels of cellular damage in normal FT organ explants maintained in culture were approximately $8 \%$, as measured by the release of $\mathrm{LDH}$ into culture medium (Fig. 1). Infection with Ngo induced a dose-dependent increase in cellular damage in FT organ cultures (Fig. 1). No significant difference was observed in the level of cellular damage induced by infection with the lowest concentration of Ngo tested (3 x $\left.10^{5} \mathrm{cfu} / \mathrm{mL}\right)$ compared to uninfected explants. Infection with $3 \times 10^{6}$ $\mathrm{cfu} / \mathrm{mL}$ of bacteria induced significant cellular damage by $12 \mathrm{~h}$, which reached a level of $20 \%$ by $24 \mathrm{~h}$. The highest concentration of $\mathrm{Ngo}\left(3 \times 10^{7} \mathrm{cfu} / \mathrm{mL}\right)$ induced significant cellular damage at all time points compared with uninfected explants, rising to a maximum level of $30 \%$ after 24 hours (Fig. 1).

Infection with Ngo induces an increased level of iNOS but not eNOS mRNA transcripts

Gonococcal infection induced high levels of iNOS mRNA $(\mathrm{p}<0.05)$ by $12 \mathrm{hrs}$ (mean levels of relative expression to PPIA of 
350AU compared with uninfected explants (10AU)) (Fig. 2). By contrast, there was no significant expression of eNOS mRNA in the presence or absence of gonococcal infection (mean levels of relative expression to PPIA $<1.5 \mathrm{AU} ; \mathrm{p}>0.05)$.

Decreased NOS enzyme activity in FT organ explants infected with $\mathrm{Ngo}$

The activity of NOS in FT explants was determined by quantifying the accumulation of L-citrulline that is produced along with NO by the action of the enzyme on the substrate L-arginine.

Under normal culture conditions, Lcitrulline accumulation increased significantly by $12 \mathrm{~h}$ in uninfected explants (Fig. 3). By contrast, infection with the highest concentration of $\mathrm{Ngo}$ for $12 \mathrm{~h}$ resulted in levels of L-citrulline production that were $50 \%$ lower than the levels observed in normal FT explants $(\mathrm{p}<0.05$; Fig. 3). The reduction in L-citrulline production was not due to bacterial direct metabolism of arginine, since control experiments in which $\mathrm{Ngo}$ was incubated for $12 \mathrm{~h}$ with $\left[{ }^{3} \mathrm{H}\right] \mathrm{L}$-arginine did not affect the levels of the tritiated amino acid (data not shown).

Effect of NOS inhibitors on the cellular damage of FT infected with Ngo

FT organ explants were infected with the highest concentration of Ngo in the presence and absence of the NOS inhibitors TRIM and L-NAME and the levels of cellular damage were measured by LDH release (Fig. $4 a, b)$. There was no significant difference in

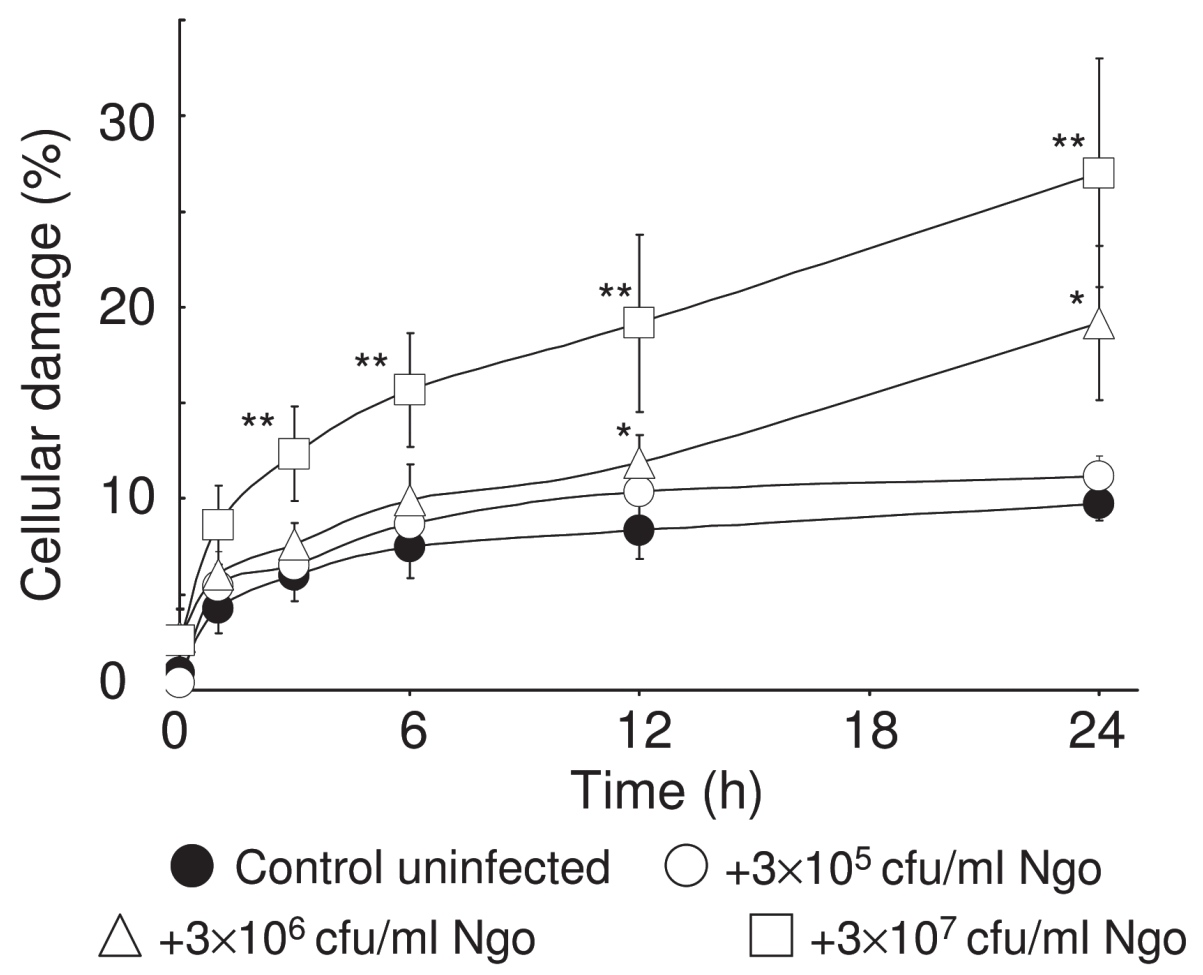

Figure 1: Neisseria gonorrhoeae induces cellular damage in culture of FT explants.

Various concentrations of bacteria were used to infect cultures of FT explants in vitro and cellular damage was quantified by release of lactate dehydrogenase (LDH) into culture medium. Data points represent the mean and standard errors of the mean of $n=4$ experiments with explants from four different donors, each treatment carried out in triplicate. The percentage of cellular damage was calculated with respect to LDH release from explants treated with Triton X-100.* $\mathrm{p}<0.05$, ** $\mathrm{p}<0.05$, compared with control FT. 
the percentage levels of cellular damage induced by Ngo in the presence or absence of TRIM (Fig. 4a). By contrast, treatment with L-NAME for $24 \mathrm{~h}$ resulted in a significant reduction by over $40 \%$ in the levels of cellular damage induced by $\mathrm{Ngo}$, compared to treatment with bacteria alone
( $\mathrm{p}<0.05$; Fig. 4b). Uninfected FT organ explants, treated with either TRIM or LNAME only showed no significant changes in the percentage levels of cellular damage (Fig. 4a, b) and, moreover, uninfected FT explants treated with the latter showed a decrease of NOS activity (data not shown).

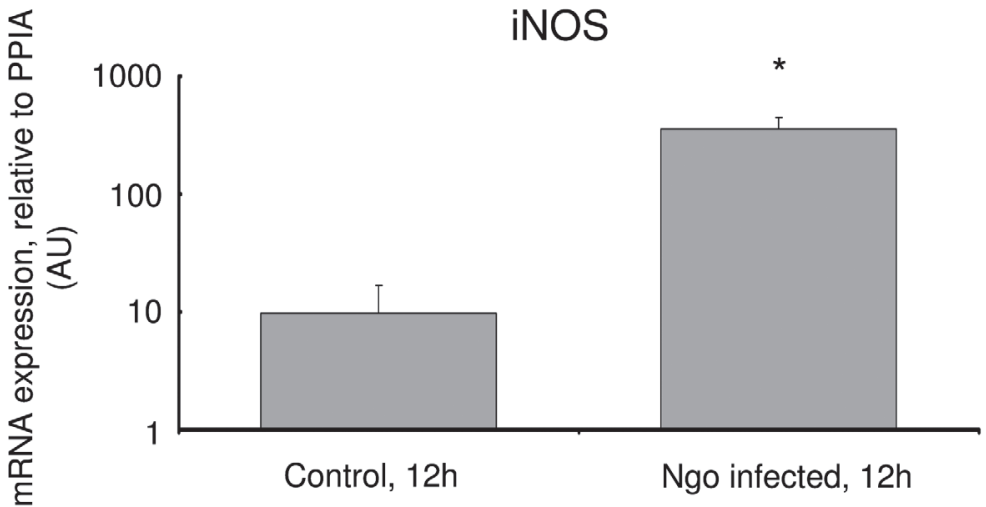

Figure 2: Determination of iNOS mRNA transcription levels Relative level of iNOS and eNOS mRNA standardized against level of PPIA mRNA of FT explants maintained for $12 \mathrm{~h}$ in the presence or absence of $\mathrm{Ngo}\left(3 \times 10^{7} \mathrm{cfu}\right.$ per explant $)$ were determined by Real time PCR. Data columns represent the mean and standard errors of the mean of $n=3$ (iNOS) experiments with explants from four different donors. ${ }^{*} \mathrm{p}<0.05$

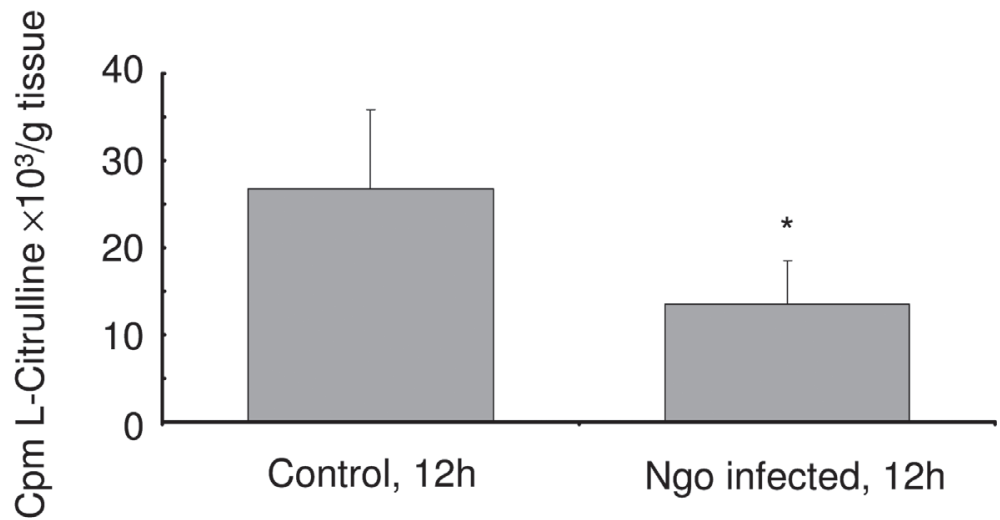

Figure 3: Indirect determination of nitric oxide (NO) production in FT explants by the measurement of nitric oxide synthase (NOS) enzyme activity.

FT explants were cultured for $12 \mathrm{~h}$ in the presence or absence of $\mathrm{Ngo}\left(3 \times 10^{7} \mathrm{cfu}\right.$ per explant $)$ and NOS activity was determined by quantifying the accumulation of L-citrulline that is produced along with nitric oxide (NO), by the action of the enzyme on the substrate L-arginine. Data columns represent the mean and standard errors of the mean of $n=4$ experiments with explants from four different donors, each treatment carried out in triplicate. ${ }^{*} \mathrm{p}<0.05$. 


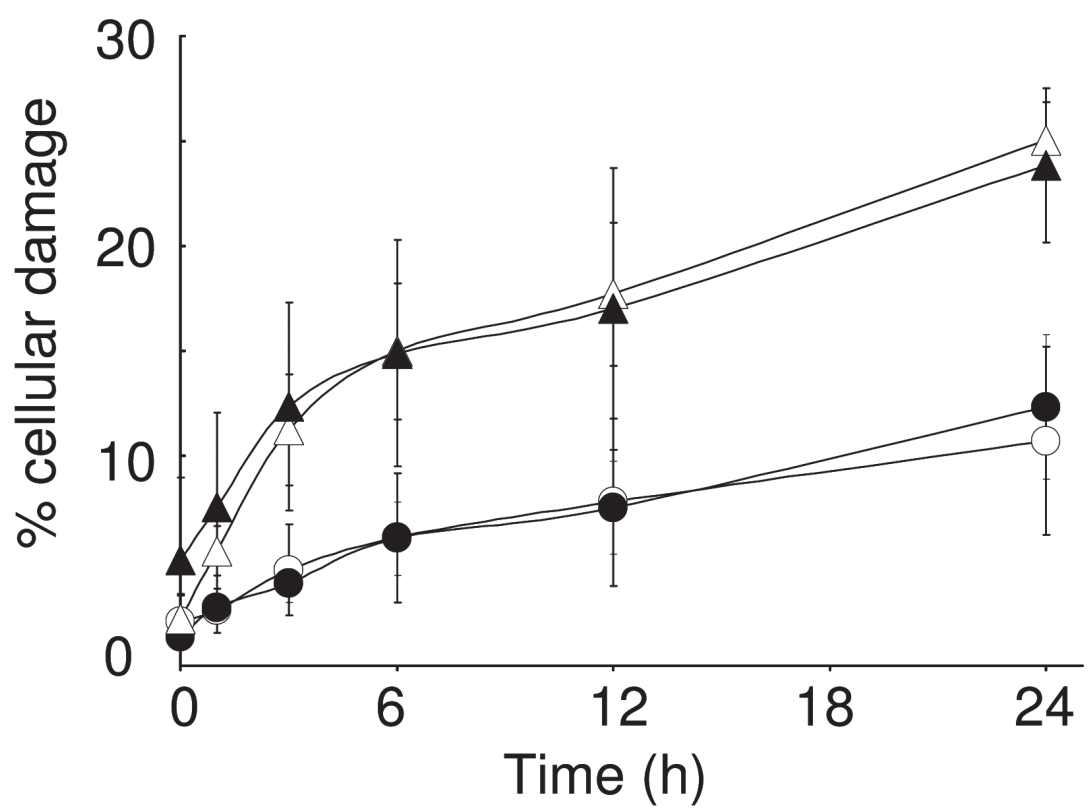

a)

$\bigcirc$ Control, uninfected FT $\triangle$ FT infected with Ngo

Control, uninfected FT + TRIM $\triangle$ FT infected with Ngo+ TRIM

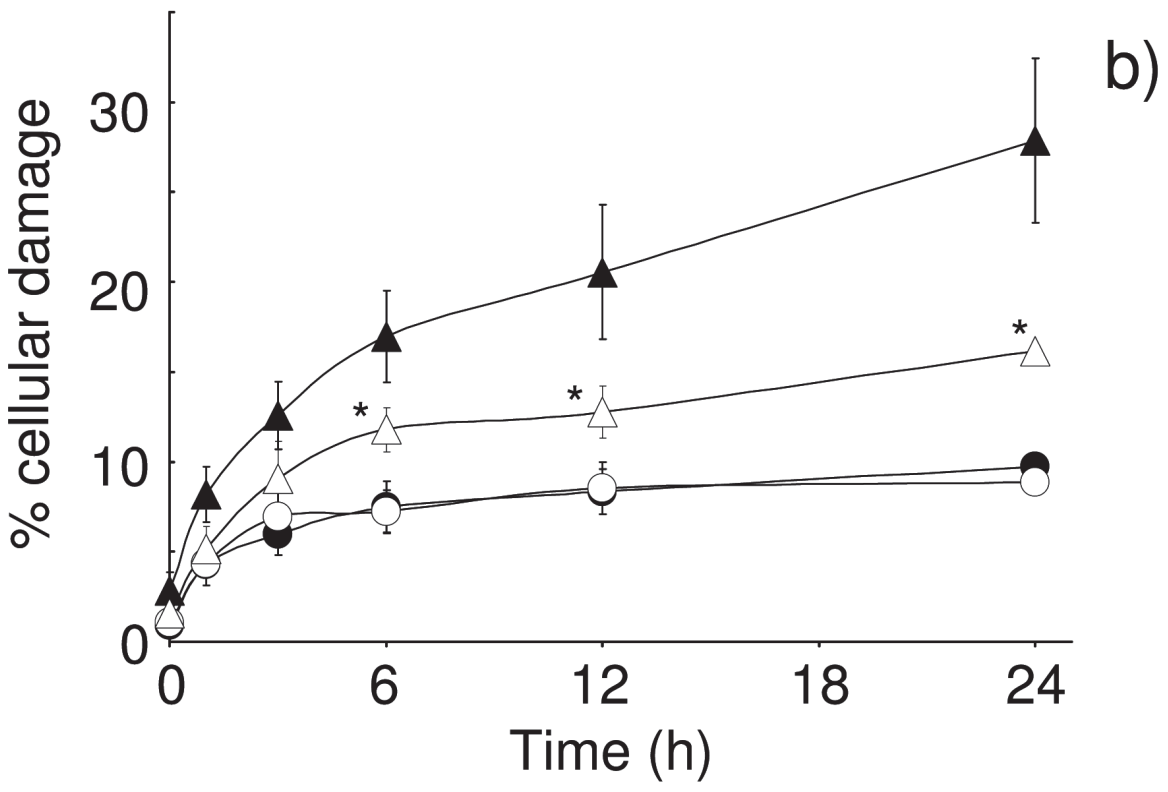

Control uninfected FT $\triangle$ FT infected with Ngo
Control FT with L-NAME $\triangle$ FT infected with Ngo+ L-NAME

Figure 4: Effect of NOS inhibitors on cellular damage induced in FT explants infected with Ngo. FT explants were infected with gonococci $\left(3 \times 10^{7} \mathrm{cfu}\right.$ per explant) in the presence or absence of the NOS inhibitors a) TRIM and b) L-NAME. Cellular damage was determined by release of lactate dehydrogenase (LDH) into culture medium. Data points represent the mean and standard errors of the mean of $n=4$ experiments with explants from four different donors, each treatment carried out in triplicate. Percentage cellular damage was calculated with respect to LDH release from explants treated with Triton X-100. * $\mathrm{p}<0.05$, compared with FT infected with Ngo alone. 
L-NAME but not TRIM impairs gonococcal viability

We next investigated whether the inhibitors affected bacterial viability. Incubation with TRIM had no effect on bacterial numbers, whereas treatment with L-NAME resulted in a significant reduction of approximately $45 \%$ of the $\mathrm{Ngo}$ cfu, compared with untreated bacteria (data not shown). This was confirmed by viable bacterial counting experiments carried out at different time points (data not shown).

SNAP has no effect on the cellular damage of FT

Treatment of FT explants for 24h with high concentrations $(100-1000 \mu \mathrm{M})$ of the exogenous NO donor SNAP did not induce any cellular damage (Fig. 5).

\section{DISCUSSION}

The role of $\mathrm{NO}$ as a multifunctional messenger is well established and its overproduction during bacterial disease is also well documented. Moreover, the antimicrobial effect of $\mathrm{NO}$ is an essential feature of innate immunity. In the current study, we investigated whether NO played a role during infection of human fallopian tube explants by Neisseria gonorrhoea (Ngo). Previous studies have shown that gonococcal infection causes significant cell death in the FT in vitro [McGee et al., 1981; Stephens et al., 1987]. In the current study, we observed an association between cell damage and increased bacteria infection and the up-regulation of iNOS, but not eNOS mRNA transcripts. In resting FT cultures, NOS enzyme activity increased with time, which could be due to the in
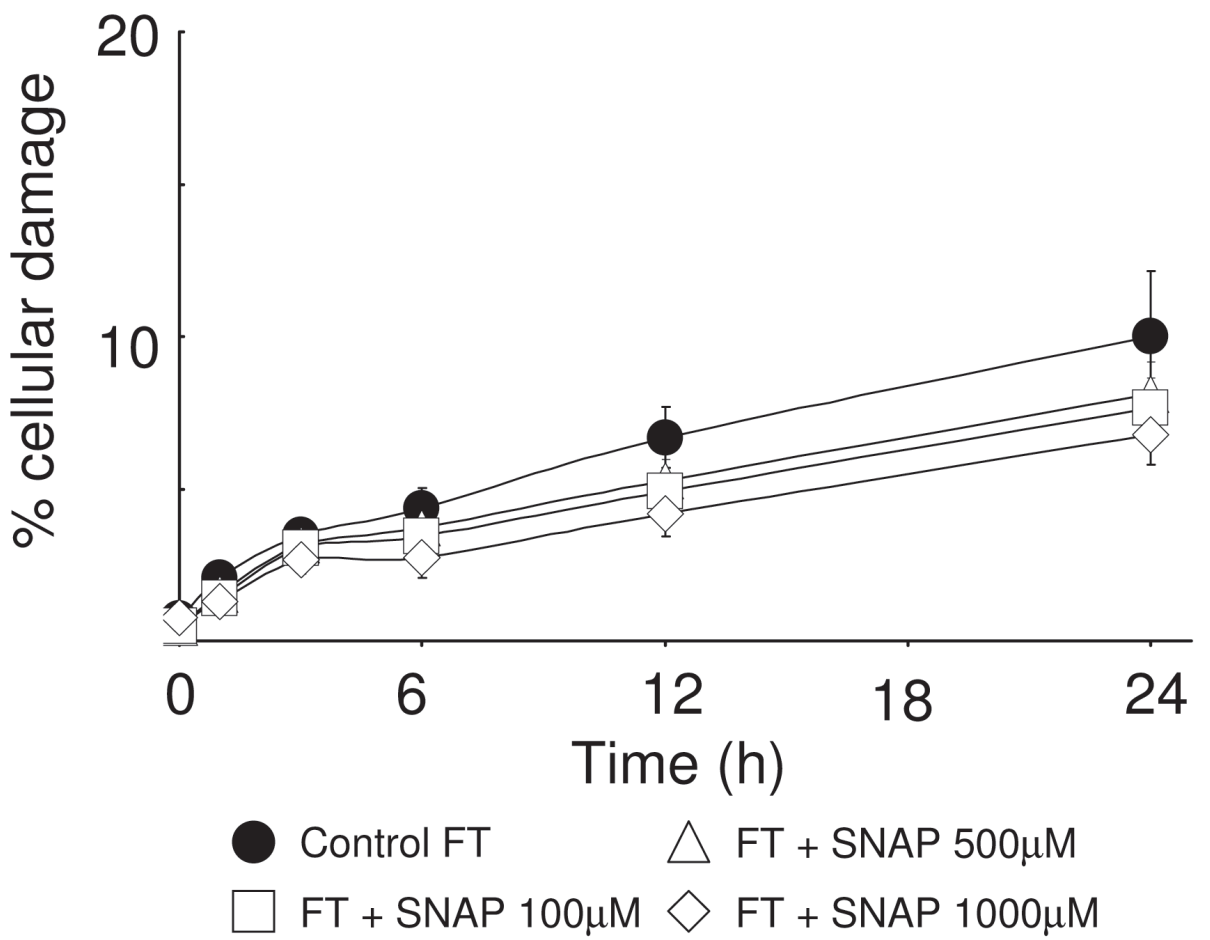

Figure 5: Effect of SNAP on cellular damage induced in FT explants uninfected Cell damage to FT explants is not induced by addition of the exogenous NO donor SNAP. FT explants were treated with increasing concentrations of SNAP (100-1000 uM) for up to $24 \mathrm{~h}$ and cellular damage was determined by release of lactate dehydrogenase (LDH) into culture medium. Data points are expressed as the mean and standard errors of the mean for $\mathrm{n}=5$ determinations. 
vitro culture conditions in an oxygen depleted environment, an observation consistent with the role of $\mathrm{NO}$ in the paracrine regulation of FT physiology [Rosselli et al., 1998]. Paradoxically, gonococcal infection led to a reduction in nitric oxide synthase (NOS) enzyme activity, despite the increase in iNOS mRNA transcription. It is possible that this inhibition of NOS activity occurs via inhibition of translation of iNOS mRNA to enzyme and this could be due host cell metabolism directing extracellular arginine deprivation or over expression of intracellular arginase [Junghee et al., 2003]

Although gonococci did not metabolize arginine directly, several other bacterial factors could be involved in reducing NOS enzyme activity in the FT. Under anaerobic conditions, Ngo can produce and degrade NO, by using nitrite reductase (AniA) [Mellies et al., 1997] to convert nitrite to $\mathrm{NO}$ and the nitric oxide reductase (NorB) to convert NO to nitrous oxide [Householder et al., 2000]. At the transcriptional level, the gonococcal repressor NsrR has been suggested to act as a NO-sensing transcription factor and postulated to play a critical role in gonococcal evasion of host NO production [Overton et al., 2006]. Recently, the gonococcal lipoprotein cytochrome c' protein has been reported to bind NO in vitro [Turner et al., 2005] and in the presence of host NO production, gonococci were also shown to reduce the levels of NO from pro-inflammatory $(>1$ $\mu \mathrm{M})$ to anti-inflammatory $(\sim 100 \mathrm{nM})$ concentrations [Cardinale and Clark, 2005]. NO degradation has also been observed with other pathogens. Trichomonas vaginalis, which causes the widespread sexually transmitted disease trichomoniasis, has recently been reported to degrade NO under anaerobic conditions, possibly through expression of an A-type flavoprotein [Sarti et al., 2004]. It is also possible that gonococci are protected from the cytotoxicity of NO during the host intracellular stage of their life cycle. It has been reported that other intracellular pathogens have evolved mechanisms to protect against NO; for example, Salmonella has been shown to express a pathogenicity island Spi2 to mediate protection [Chakravortty and Hensel, 2003] and Citrobacter rodentium modulates iNOS activity so that local NO concentrations surrounding bacteria are low, whereas NO activity is high in areas distant from infection [Vallance et al., 2002].

In order to investigate further the role of NO during gonococcal infection of FT in vitro, we also investigated whether NOS inhibitors or a NO donor influenced the levels of induced cellular damage. The addition of the NO donor SNAP did not induce cellular damage in FT explants, suggesting that the FT has protective mechanisms for preventing cell death, as cell viability is important for the normal FT functions of transporting gametes and embryos. In the case of the NOS inhibitors, TRIM failed to prevent gonococcal-induced cellular damage, whereas the addition of LNAME resulted in significant cell protection. This was probably a result of activity of this L-arginine analogue towards gonococci; it is possible that competition of L-NAME reduces the level of available Larginine and gonococci could then be unable to supplement growth by denitrification.

The FT epithelium plays an active role in innate immunity by production of the antimicrobial NO. Thus, the biological significance of the reduction of NOS activity and defence mechanism, induced by gonococcal infection observed in the current study, is likely to be an increase in the susceptibility of the FT to ascending infection. As a consequence, gonococcal adherence to the FT epithelium and subsequent invasion leads to cell death and the development of salpingitis. The effect of gonococcal infection on NOS activity in primary FT epithelia contrasts with that recently reported by Edwards [2010] with primary cervical epithelial cells in vitro. In the latter study, NOS activity and NO production by cervical epithelial cells was increased by gonococcal infection and this promoted survival of bacteria within the cells. However, this particular increase in NO was dependent on a progesterone-rich environment, whereas in our study the hormone was absent. Thus, it appears that 
gonococci can use hormone-dependent and independent mechanisms to modulate NOS activity and NO production throughout the female reproductive tract and that both mechanisms result in the increased pathogen interaction with mucosal epithelial cells.

In summary, our data suggest that nitric oxide is not responsible for cellular damage induced during gonococcal infection of the human FT in vitro and it is unlikely to be involved in the death of ciliated epithelial cells observed in vivo. Our findings contrast with the study of Heiss and colleagues on Bordetella pertussis infection of ciliated cells of the trachea [Heiss et al., 1994]. B. pertussis infection was shown to produce NO that mediated the cytotoxicity of the pathogen-secreted tracheal cytotoxin, which resulted in the death of ciliated tracheal cells [Heiss et al., 1994]. Thus, it appears that ciliated epithelial cells from different sites of the body respond differently to bacterial infection with respect to NO production and cytotoxicity. This is likely to be due to cellular recognition of different pathogen associated molecular patterns expressed by these organisms. Indeed, the ability of gonococci to regulate $\mathrm{NO} / \mathrm{NOS}$ activity is likely to provide the organism with a selective advantage in colonization of the mucosal epithelium of the female upper reproductive tract.

Moreover, our study also suggests the presence of a privileged mechanism of oxidative damage control in the FT, which adds further knowledge regarding the pathophysiology of the FT infection.

\section{ACKNOWLEDGEMENTS}

This work was supported by grants received from FONDECYT 1090589, DICYT and Proyecto BASAL FB0807.

\section{REFERENCES}

BARRETT S, TAYLOR C. (2005). A review on pelvic inflammatory disease. International Journal of Std \& Aids. 16: 715-721.

BLAISE G, GAUVIN D, GANGAL M, AUTHIER S. (2005). Nitric oxide, cell signalling and cell death. Toxicology. 208: 177-192.
BRUCKDORFER R. (2005). The basics about nitric oxide Mol.Aspects Med. 26: 3-31.

BURGNER D, ROCKETT K, KWIATKOWSKI D. (1999). Nitric oxide and infectious diseases. Archives of Disease in Childhood 81: 185-188.

BUSSE R, MULSCH A (1990). Induction of Nitric-Oxide Synthase by Cytokines in Vascular Smooth-Muscle Cells. Febs Letters 275: 87-90.

CARDINALE JA, CLARK VL. (2005). Determinants of nitric oxide steady-state levels during anaerobic respiration by Neisseria gonorrhoeae. Mol. Microbiol. 58: $177-188$.

CATES W, ROLFS RT, ARAL SO. (1990). Sexually Transmitted Diseases, Pelvic Inflammatory Disease, and Infertility -An Epidemiologic Update. Epidemiologic Reviews. 12: 199-220.

CHAKRAVORTTY D, HENSEL M. (2003). Inducible nitric oxide synthase and control of intracellular pathogens. Microbes and Infection. 5: 621-627.

DINARELLO CA. (2002). The IL-1 family and inflammatory diseases. Clinical and Experimental Rheumatology 20: S1-S13.

EDWARDS JL. (2010). Neisseria gonorrhoeae survival during primary, human cervical epithelial cell infection requieres nitric oxide and is augmented by progesterone. Infect Immun. 2010 Jan 4

EKERHOVD E, BRANNSTROM M, WEIJDEGARD B, NORSTROM A. (1999). Localization of nitric oxide synthase and effects of nitric oxide donors on the human Fallopian tube. Mol Hum Reprod. 5: 10401047.

GOODRUM KJ, POULSON-DUNLAP J. (2002). Cytokine responses to group B streptococci induce nitric oxide production in respiratory epithelial cells. Infect.Immun. 70: 49-54.

GORBY GL, SCHAEFER GB. (1992). Effect of attachment factors (Pili Plus Opa) on Neisseria gonorrhoeae invasion of human Fallopian tube tissue in vitro Quantitation by Computerized Image Analysis. Microb.Path. 13: 93-108.

GREGG CR, MELLY MA, HELLERQVIST CG, CONIGLIO J, MCGEE ZA. (1981). Toxic activity of purified lipopolysaccharide of Neisseria gonorrhoeae for human fallopian tube mucosa. J.Infect.Dis. 143: 432-439.

GRIMMINGER F, ROSE F, SIBELIUS U, MEINHARDT M, POTZSCH B. (2007). Human endothelial cell activation and mediator release in response to the bacterial exotoxins Escherichia coli hemolysin and staphylococcal alpha-toxin. J.Immunol. 159: 19091916.

GRODSTEIN F, ROTHMAN KJ. (1994). Epidemiology of Pelvic Inflammatory Disease. Epidemiology. 5: 234242.

HEISS LN, LANCASTER JR JR, CORBETT JA, GOLDMAN WE (1994). Epithelial autotoxicity of nitric oxide: role in the respiratory cytopathology of pertussis. PNAS. 91: 267

HENRÍQUEZ S, TAPIA A, QUEZADA M, VARGAS M, CÁRDENAS H, RÍOS M, SALVATIERRA AM, CROXATTO H, ORIHUELA P, ZEGERSHOCHSCHILD F, MUNROE DJ, VELÁSQUEZ L. (2006). Deficient expression of monoamine oxidase A in the endometrium is associated with implantation failure in women participating as recipients in oocyte donation. Mol Hum Reprod. 12: 749-54.

HOBBS AJ, HIGGS A, MONCADA S. (1999). Inhibition of nitric oxide synthase as a potential therapeutic target. Annual Review Of Pharmacology And Toxicology. 39: 191-220. 
HOUSEHOLDER TC, FOZO EM, CARDINALE JA, CLARK VL. (2000). Gonococcal nitric oxide reductase is encoded by a single gene, nor $B$, which is required for anaerobic growth and is induced by nitric oxide. Infect.Immun. 68: 5241-5246.

HOYME UB. (1990). Pelvic inflammatory disease and associated sexually-transmitted diseases. Curr. Op. Obstet. Gynecol. 2: 668-674.

JUNGHEE LEE, HOON RYU, ROBERT J. FERRANTE, SIDNEY M. MORRIS, JR, AND RAJIV R. RATAN. (2003). Translational control of inducible nitric oxide synthase expression by arginine can explain the arginine paradox. PNAS. 100 (8): 4843-4848.

KAO CL, CHIOU SH, CHEN HS, HO DMT, CHENCF. (2003). Elevated nitric oxide levels in childhood brain tumors. Childs Nervous System. 19: 744-749.

KAWAKAMI Y, MONOBE M, KUWABARA K, FUJITA T, MAEDA M (2006). A comparative study of nitric oxide, glutathione, and glutathione peroxidase activities in cerebrospinal fluid from children with convulsive diseases/children with aseptic meningitis. Brain \& Development. 28: 243-246.

KIM JM, KIM JS, JUNG HC, OH YK, CHUNG HY. (2003). Helicobacter pylori infection activates NFkappa B signaling pathway to induce iNOS and protect human gastric epithelial cells from apoptosis. American Journal of Physiology-Gastrointestinal and Liver Physiology. 285: G1171-G1180

KLEINERT H, SCHWARZ PM, FORSTERMANN U. (2003). Regulation of the expression of inducible nitric oxide synthase. Biological Chemistry, 384: 1343-1364.

KLIMENKO O. (2004). Concentrations of nitric oxide and inflammatory cytokines in cerebrospinal fluid of children with different stages of meningitis. Nitric Oxide-Biology and Chemistry. 11: 105-106.

MAISEY K, NARDOCCI G, IMARAI M, CARDENAS H, CROXATTO HB, HECKELS J, CHRISTODOULIDES M, VELASQUEZ LA. (2003). Expression of proinflammatory cytokines and receptors by human fallopian tubes in organ culture following challenge with Neisseria gonorrhoeae. Infect.Immun. 71: 527532.

MARRIOTT HM, ALI F, READ RC, MITCHELL TJ, WHYTE MKB. (2004). Nitric oxide levels regulate macrophage commitment to apoptosis or necrosis during pneumococcal infection. Faseb Journal. 18: 1126

MCCORMACK WM. (1994). Pelvic inflammatory disease. N.Eng.J.Med. 330: 115-119.

MCGEE ZA, JOHNSON AP, TAYLOR-ROBINSON D. (1976). Human fallopian tubes in organ culture: preparation, maintenance and quantitation of damage by pathogenic microorganisms. Infect. Immun. 13: 608-618.

MCGEE ZA, JOHNSON AP, TAYLOR-ROBINSON D. (1981). Pathogenic mechanisms of Neisseria gonorrhoeae: observations on damage to human fallopian tube mucosa in organ culture by gonococci of colony type 1 or type 4. J.Infect.Dis. 143: 413-422.

MCGEE ZA, STEPHENS DS, HOFFMAN LH, SCHLECH WF, HORN RG. (1983). Mechanisms of mucosal invasion by pathogenic Neisseria. Rev.Infect.Dis. 5: S708-S714

MCGEE ZA, CLEMENS CM, JENSEN RL, KLEIN JJ, BARLEY L. (1992). Local induction of tumor necrosis factor as a molecular mechanism of mucosal damage by gonococci. Microb.Path. 12: 333-341.

MCGEE ZA, JENSEN RL, CLEMENS CM, TAYLORROBINSON D, JOHNSON AP. (1996). Gonococcal infection of human fallopian tube mucosa in organ culture: Relationship of mucosal tissue TNF-alpha concentration to sloughing of ciliated cells. Sexually Transmitted Diseases. 26: 160-165.

MELLIES J, JOSE J, MEYER TF. (1997).The Neisseria gonorrhoeae gene aniA encodes an inducible nitrite reductase. Molecular \& General Genetics. 256: 525532 .

MELLY MA, GREGG CR, MCGEE ZA (1981). Studies of toxicity of Neisseria gonorrhoeae for human fallopian tube mucosa. J.Infect.Dis. 143: 423-431.

MELLY MA, MCGEE ZA, ROSENTHAL RS. (1984). Ability of monomeric peptidoglycan fragments from Neisseria gonorrhoeae to damage human fallopian tube mucosa. J.Infect.Dis. 149: 378-386.

MORALES P, REYES P, VARGAS M, RIOS M, IMARAI CM, CARDENAS H, CROXATTO H, ORIHUELA P, VARGAS R, FUHRER J, HECKELS JE, CHRISTODOULIDES M, VELASQUEZ L. (2006). Infection of human Fallopian tube epithelial cells with Neisseria gonorrhoeae protects cells from tumour necrosis factor (TNF)- $\alpha$ induced apoptosis. Infect.Immun. 74: 3643-3650.

OVERTON TW, WHITEHEAD R, LI Y, SNYDER L, SAUNDERS N. (2006). Coordinated regulation of the Neisseria gonorrhoeae-truncated denitrification pathway by the nitric oxide-sensitive repressor NsrR and nitrite-insensitive NarQ-NarP. J Biol Chem. 281: 33115-33126.

PLUM J, TABATABAEI MM, LORDNEJAD MR, PIPINIKA O, RAZEGHI P (1999). Nitric oxide production in peritoneal macrophages from peritoneal dialysis patients with bacterial peritonitis. Peritoneal Dialysis International. 19: S378-S383

ROSSELLI M, KELLER PJ, DUBEY RK. (1998). Role of nitric oxide in the biology, physiology and pathophysiology of reproduction. Human Reproduction Update. 4: 3-24

SARTI P, FIORI PL, FORTE E, RAPPELLI P, TEIXEIRA M. (2004). Trichomonas vaginalis degrades nitric oxide and expresses a flavorubredoxin-like protein: a new pathogenic mechanism? Cell.Molec.Life Sci. 61: 618-623.

SMALLWOOD HS, SHI L, SQUIER TC (2006). Increases in calmodulin abundance and stabilization of activated inducible nitric oxide synthase mediate bacterial killing in RAW 264.7 macrophages. Biochemistry. 45: 97179726.

STACEY CM, MUNDAY PE, TAYLORROBINSON D, THOMAS BJ, GILCHRIST C. (1992). A longitudinal study of pelvic inflammatory disease. British Journal Of Obstetrics And Gynaecology. 99: 994-999.

STEPHENS DS, MCGEE ZA, COOPER MD. (1987). Cytopathic effects of the pathogenic Neisseria -studies using human Fallopian tube organ cultures and human nasopharyngeal organ cultures. Antonie Van Leeuwenhoek Journal of Microbiology. 53: 575-584.

THIEMERMANN C, WU CC, SZABO C, PERRETTI M, VANE JR (1993). Role of Tumor-Necrosis-Factor in the Induction of Nitric-Oxide Synthase in A Rat Model of Endotoxin-Shock. British Journal of Pharmacology, 110: 177-182.

TURNER SM, MOIR JWB, GRIFFITHS L, OVERTON TW, SMITH H. (2005). Mutational and biochemical analysis of cytochrome c, a nitric oxide-binding lipoprotein important for adaptation of Neisseria gonorrhoeae to oxygen-limited growth. Biochemical Journal. 388: 545-553.

VALLANCE BA, DENG W, DEGRADO M, CHAN C, JACOBSEN K. (2002). Modulation of inducible nitric oxide synthase expression by the attaching and effacing 
bacterial pathogen Citrobacter rodentium in infected mice. Infect.Immun. 70: 6424-6435.

VÁSQUEZ G, SANHUEZA F, VÁSQUEZ R, GONZÁLEZ M, SAN MARTÍN R, CASANELLO P, SOBREVIA L. (2004). Role of adenosine transport in gestational diabetes-induced L-arginine transport and nitric oxide synthesis in human umbilical vein endothelium. Journal of Physiology-London. 560: 111-122.

VIRJI M, HECKELS JE. (1986). The effect of protein II and pili on the interaction of Neisseria gonorrhoeae with human polymorphonuclear leukocytes. J. Gen Microbiol. 132: 503-512.

WARD ME, WATT PJ, ROBERTSON JN. (1974). The human fallopian tube: a laboratory model for gonococcal infection. J. Infect. Dis. 129: 650-659.
WARD ME, WATT PJ, ROBERTSON JN. (1974). The human fallopian tube: a laboratory model for gonococcal infection. J. Infect. Dis. 129: 650-659.

WESTROM L, WOLNERHANSSEN P. (1993). Pathogenesis of pelvic inflammatory disease. Genitourin Med. 69: 9-17.

WHEELER MA, SMITH SD, GARCIA CARDENA G, NATHAN CF, WEISS RM. (1997). Bacterial infection induces nitric oxide synthase in human neutrophils. J.Clin.Invest. 99: 110-116.

WITTHOFT T, ECKMANN L, KIM JM, KAGNOFF MF. (1998). Enteroinvasive bacteria directly activate expression of iNOS and NO production in human colon epithelial cells. American Journal of PhysiologyGastrointestinal and Liver Physiology. 38: G564-G571. 